\title{
RESILIENCE IN IGBO RURAL COMMUNITY ADOLESCENTS AND YOUNG ADULTS
}

\author{
${ }^{1}$ JohnBosco Chika Chukwuorji and ${ }^{2}$ Chukwuedozie K. Ajaero \\ ${ }^{1}$ Department of Psychology, \\ ${ }^{2}$ Department of Geography, \\ University of Nigeria, Nsukka 41000, Enugu State, Nigeria
}

Received 2014-06-30; Revised 2014-07-03; Accepted 2014-07-19

\begin{abstract}
While involved in organising an empowerment seminar for the Igbo rural youths, the authors investigated resilience among rural adolescents and young adults. Three hundred and twenty nine (329) adolescents $(\mathrm{n}=$ 162) and young adults $(n=167)$, comprising 159 males and 170 females, were participants. They completed the 14-item Resilience scale and provided some relevant demographic information. Analysis Of Variance (ANOVA) was used to test for differences in resilience on account of age, gender and level of education. Young adults had significantly higher resilience scores than adolescents. No significant difference was found in resilience scores of males and females. Participants with higher education had significantly higher resilience scores than those with lower education. Of all the interaction effects tested, only age $*$ gender $*$ education had a significant interaction effect on resilience. Discussion of the findings were based on the literature, realities of life in contemporary Igbo society and the authors' observations.
\end{abstract}

Keywords: Adolescents, Education, Igbo, Resilience, Young Adults

\section{INTRODUCTION}

The origins of resilience science have deep roots in the history of medicine, psychology and education (Masten, 1989; Masten and Coatsworth, 1998); and it has been recently suggested that resilience science and positive youth development shares a common goal of promoting positive development (Masten, 2014). However, it was around 1970 that systematic investigations of resilience emerged within the wider interdisciplinary field of developmental psychopathologythe study of behavioural health and adaptation from a developmental perspective (Masten and Coatsworth, 1998; Masten, 2006). The growing emphasis on resilience in behavioural health and adaptation signals a fundamental shift from deficit-oriented frameworks to asset-enhancing or strength-based approaches (Epps and Jackson, 2000). In this developmental research context, resilience is the "process of, capacity for or outcome of successful adaptation despite challenging or threatening circumstances" (Masten et al., 1990). The resilience construct opened up the possibility of studying strengths and to design programmes that build capacity and competence rather than address risks. Hence across research and practice, a growing body of work has used resilience as a framework to understand individual responses to stress as well as important contributors to healthy development across the lifespan (Luthar et al., 2000). Therefore, promoting resilience may pave the way for long term outcomes by enhancing the chances of positive adaptations in future, even if optimal environmental conditions for growth are unattainable (Newman and Blackburn, 2002; Newman, 2004; Riches et al., 2009).

Resilience is a quality that shapes the way individuals cope with adversity (Liddle, 1994). It is also the ability to recover effectively from daily stress and challenges of life (Ryff et al., 1998; Davda, 2011). Wagnild and Young (1990) delineated five underlying characteristics

Corresponding Author: JohnBosco Chika Chukwuorji, Department of Psychology, University of Nigeria, Nsukka 41000, Enugu State, Nigeria 
of resilience to include meaningful life/purpose, perseverance, equanimity, self-reliance and existential aloneness, which have also been discussed elsewhere (Wagnild 2011; Davda, 2011; Ifeagwazi et al., 2014). Such resilient attitudes have also been observed in earlier studies (Wanberg and Banas, 2000; Warner, 2009). These characteristics become relevant to young persons in fostering adaptive capacity because compared to other groups, adolescents and young adults often bear the consequences of inadequate social resources and hardship. Apparently, a resilience-based approach to positive life adaptation is people-focused and reflects the distinct capacities and coping mechanisms of various socio-demographic groups as well as other contextually relevant variables (Ungar, 2008; GSCP, 2013). Context in this sense embraces the broad social/environmental conditions such as education, geography, culture and so on. As a result, resilience must be viewed as an interplay of the individual and the broader environment, a balance between stress and coping and a dynamic developmental process which is important at life transitions (Masten, 1994).

According to the resilience model (Richardson, 2002; Richardson and Waite, 2002), if an people experience a disruption when a stressor is encountered, they rely on internal protective factors (such as self-reliance and good health) as well as external protective factors (such as social relationships) to restore balance to their lives. In this experiential process, resilient characteristics are integrated so that life events become routine and do not result in significant disruption. This resilience model is congruent with ecological systems theory (Bronfenbrenner, 1979) which views the individual as developing within a complex system of relationships affected by multiple levels of the surrounding environment (Howard and Johnson, 2009). On this basis, while it is known that many of the resilience processes are shared, a tension remains in the literature accounting for both homogeneity and heterogeneity in manifestations of resilience among different populations and groups. This is not unexpected since resilience may be understood as an interactive process of personal and social ecologies. Hence, resilience research is becoming increasingly focused on patterns of resilience in various cultures and contexts (Ungar, 2008) and there is substantive scope for new knowledge on resilience in unexamined and underrepresented rural populations such as the Igbo ethnic group. This need may be further informed by the societal value of sustained research interest in rural communities, particularly in an age of globalisation (Sumner, 2005; UNDP, 2008; Young,
2012; Ajaero and Madu, 2013). It is reasoned that by extending empirical investigations of resilience in such populations as the Igbos of Nigeria, a deeper appreciation of the developmental context of resilience will be achieved. The rural situation in sub-Saharan Africa and Igbo land in particular, also presents unique opportunities and challenges for resilience.

Furthermore, Relational Competence Theory (RCT) includes resilience as one aspect of competence. It attempts to capture the process of socialisation that occurs through continuous interaction with significant others in exchange relationships (Miller, 1986; Gianesini et al., 2010; L'Abate, 2010; L'Abate et al., 2010; Wild et al., 2011). In this perspective, resilience is appraised as a relational (social, cognitive and emotional) construct which varies across gender lines and changes throughout life stages and across cultural contexts (Sexton et al., 2010). The present study adds to existing resilience literature by examining socio-demographic factors in resilience among adolescents and young adults in a remote rural community in Igbo land. Ibeagha et al. (2004) investigated resiliency in an inner-city sample but the participants were Yoruba university undergraduates in southwestern Nigeria. The focus of Ibeagha et al. (2004) study was not on the demographic factors that may influence resilience. We considered the demographic variables in the current study because of Weisner et al. (2004) position that demographic context remains one of the approaches to dealing with social vulnerability.

\subsection{Rural Geography and Economy in Igboland}

Igboland, in which the study area is situated, lies between latitudes $4^{0} 45^{\prime}$ and $7^{0} 05^{\prime}$ north and longitudes $6^{0} 00^{\prime}$ and $8^{0} 31^{\prime}$ east. With a total surface area of approximately 41,000 square kilometres, Igbos of Nigeria had a population of $22,926,340$ and a population density of 559 persons per square kilometre according to the Nigeria's 2006 population census results (Ofomata, 2010). The land surface is characterized mainly of plains less than 200 metres above sea level while the mean rainfall varies from about $1500 \mathrm{~mm}$ at extreme north to above $2500 \mathrm{~mm}$ in the southern part of Igbo land. Four major vegetation units exist in Igboland from the north to the south namely, the rain forest-savanna ecotone, the lowland rain forest, the fresh water swamp forest and the salt water swamp forest.

The Igbo rural economy is dominated by agriculture, trade and local craft manufacturing (Anene, 1979). However, agriculture remains the main stay of the economy of the Igbo people. The major agricultural products are yams and cassava (Achebe, 1994). Other 
important subsidiary crops include cocoyam, plantain, maize, melon, okra, pumpkin, pepper, gourd and beans. Palm products are the main cash crops. The principal exports include palm oil and, to a lesser extent, palm kernels. In addition, local crafts and wage labour are important in the rural Igbo economy. For instance, the Igbo blacksmiths are renowned for their iron smiting while men's wood carving and women's pottery and patterned woven cloth are of very high quality Another major social and economic function in traditional Igbo society is trading as they can be found engaged in buying and selling of various commodities in different parts of Nigeria and beyond. With regards to labour, there is a sexual division of labour in the traditional setting. Men are mainly responsible for yam cultivation and women for other crops which include cassava, cocoyam and pumpkin. When it comes to palm products, the men usually cut the palm fruit and tap and then sell the palm wine. They also sell palm oil, which the women prepare. In general, women reserve and sell the kernels (Njoku, 1990; Ogbaa, 1995). The young men and women are socialised accordingly in these occupations. However, due to the social transformations in contemporary Nigerian society, many people migrate to the cities and crave for the unavailable modern occupations such as public service jobs. Historically, the Igbos are believed to have a Jewish origin.

\subsection{Age and Resilience}

In the conceptual resilience cycle (Davda, 2011), age was one of the factors that account for resilience. Indeed, some resilience factors reflect the stage of development a person has reached and the connection is cumulative as what is acquired in earlier developmental stages is carried on to later stages of development (Grotberg, 2005). Thus, in the growth process among young people, each stage is characterised by a set of different skills, needs and expectations (UNICEF, 2013). Adolescence, in particular, may provide unique opportunities for both risks and resilience unlike young adulthood. However, empirical findings on age effects on resilience are mixed. Some studies have shown a positive relationship between age and resilience (Bolognini et al., 1996; St. Jean et al., 2001; Frost and McKelvie, 2004; Sun and Stewart, 2007; Salazar-Pousada et al., 2010; Torma, 2010; Wagnild, 2011; Gooding et al., 2011) while others reported that resilience decreases with age (Condly, 2006; Schoon, 2006; Riches et al., 2009). Evidently, most of the existing studies have investigated age effects on resilience within the same cohort of adolescents or between children and adolescents while others were among young adults and older adults. There is scarce empirical literature which have compared rural adolescents and young adults on resilience. Adolescents living in rural areas may experience unique stressors related to the socio-cultural context of their community. We, therefore, expect that Igbo young adults will report significantly higher resilience than adolescents $\left(\mathrm{H}_{1}\right)$.

\subsection{Gender and Resilience}

Some global policy frameworks for resilience promotion (Holmes and Jones, 2009; GSCP, 2013) upholds that building resilience needs to be gendersensitive. Evidence of gendered psychological resources (e.g., agency, mastery and worth) in favour of males which may provide the requisite foundation to enable resilience characteristics (Shanahan and Hofer, 2005) have been supported by studies showing higher resilience in adolescent males compared to females (Campbell-Sills et al., 2009; von Soest et al., 2010; Waaktaar and Torgersen, 2012; Abukari and Laser, 2013; Stratta et al., 2013; Ying et al., 2014). Among older populations, males have also been found to report higher resilience (Boardman et al., 2008). However, substantial empirical literature indicates that females have higher resilience than males in diverse groups such as children (Werner, 1985; Sun and Stewart, 2007; Riches et al., 2009), adolescents (Chung and Elias, 1996; Hair et al., 2001; Hampel and Petermann, 2005; Arokiaraj et al., 2011) and adults (Netuveli et al., 2008; Wagnild, 2011; Ma et al., 2013).

But few studies demonstrated a lack of significant difference in resilience between genders (Aronen and Kurkela, 1998; Campbell-Sills et al., 2006). To the knowledge of the researchers in the current study, gender differences in resilience in rural samples have not been investigated, especially among Igbos. We hypothesise that Igbo adolescent males and young adults who are males will report significantly higher resilience than the females $\left(\mathrm{H}_{2}\right)$. Some researchers have reported significant interaction effect of age and gender in resilience (Gamble and Zigler, 1986; Sun and Stewart, 2007; Rutter, 1989). We shall also examine the interaction effect of the demographic variables on resilience in this study.

\subsection{Education and Resilience}

Education has been recognised to contribute to enhanced levels of resilience for community. Specifically, the skills, opportunities and relationships 
that promote resilience can be provided in schools (Storer et al., 1995) and schools play an inevitable part in linking knowledge to action and bringing about appropriate future decision-making (Frankenberg et al., 2013; Thimythi and Sha, 2013). The role of education in resilience promotion aligns with observations that lower level of education is a vulnerability factor in psychopathology (Ahmed, 2007). Empirical research also demonstrated the transformative role of education in resilience promotion (Ma et al., 2013; Krasny et al., 2010). There is paucity of research on the role of education in resilience of rural adolescents and young adults. We expect that Igbo adolescents and young adults who have higher levels of education will report significantly higher resilience than those who have lower education $\left(\mathrm{H}_{3}\right)$.

\section{MATERIALS AND METHODS}

\subsection{Participants}

Three hundred and twenty nine (329) Igbo adolescents $(n=162)$ and young adults $(n=167)$ in Nenwe community located in Aninri Local Government Area of Enugu state, Nigeria, participated in this study. The area has a total population of 33, 723 residents at the most recent (2006) Nigerian Census and is located approximately $10 \mathrm{~km}$ outside the major metropolitan Igbo central city of Enugu. Like all other rural communities in Igbo land, the predominant industry is agriculture with a substantial portion of its population engaged in farming (75\%), although trading (15\%) and public service (12\%) are also engaged in. The rural dwellers in trading and public service also engage in some farming activities. In the total sample of study participants, 159 were males while 170 were females. Educationally, $65 \%$ have not completed high school while $35 \%$ were either high school leavers, in higher institutions or university graduates. Majority (92\%) were from monogamous families and an overwhelming majority $(97 \%)$ were single. Age range of the participants was 12-24 years with mean ages of 18.5 years (total sample), 15.08 years (adolescents) and 21.74 years (young adults). Adolescents consisted of 71 males and 91 females while young adults comprised 88 males and 79 females. They were all Christians.

\subsection{Instrument}

We used the 14-item version of Resilience scale (RS14) (Wagnild and Young, 1993) as a measure of adolescents' and young adults' capacity to withstand life stressors, thrive and make meaning from life's challenges. Some items in RS-14 include: I usually take things in stride; my life has meaning; etc. The items of the RS-14 are scaled in a positive direction on a 7-point response format ranging from 1 (strongly disagree) to 7 (strongly agree). Cronbach's $\alpha$ reliability coefficients ranging from 0.91 to 0.93 across numerous studies was reported by Wagnild and Young (1993). The concurrent administration of RS-14 and some other measures by the developers revealed significant discriminant validity coefficients with life satisfaction $(\mathrm{r}=0.37)$ morale $(\mathrm{r}=$ $0.31)$ depression $(r=-0.41)$, self-reported health status ( $r$ $=-0.30$ ); and a highly adequate convergent validity with the 25-item Resilience Scale $(r=0.97)$. It has also shown moderate divergent and convergent validity coefficients ranging from 0.29 to 0.63 when correlated with the domains of health promoting lifestyle (Wagnild and Young, 1993). Rew et al. (2001) reported discriminant validity of the RS-14 with loneliness (-0.50) and hopelessness (-0.47) measures. In a validation study for the RS-14 in Nigeria, Abiola and Udofia (2011) reported a Cronbach's $\alpha$ coefficient of 0.81 , a convergent validity of 0.97 with RS-25 as well as discriminant validity coefficients of -0.28 (Depression subscale of Hospital Anxiety Depression Scale, HADS) and -0.26 (Anxiety subscale of HADS). Ifeagwazi et al. (2014) obtained a Cronbach's $\alpha$ of 0.83 and a Spearman-Brown split-half reliability coefficient of 0.80 . Among adolescents, Cronbach's alpha ranged from 0.72-0.91 (Wagnild, 2011). Wagnild (2011) also reported a Cronbach's alpha of 0.92 among adults residing in rural communities. A Cronbach's alpha of 0.85 was obtained in the current sample. A CFA yielded one major factor which has a good fit for the data (CFI $=324.67, \mathrm{p}<0.05)$. Higher scores on the RS-14 indicate more resilient characteristics.

In addition to the RS-14 mentioned above, some demographic variables were included in the questionnaire form. They included: Age, gender (male, female), level of education (primary, junior secondary 3, O Level, Higher institution), highest qualification obtained (First School Leaving Certificate, Junior Secondary Certificate, Senior Secondary School Certificate, Ordinary Diploma/National Certificate in Education, Higher Diploma, Bachelor's degree, Master's degree), Marital status (married, single, divorced, separated), Family type (monogamy, polygamy).

\subsection{Procedure}

Consistent with recommendations (Douglas and Craig, 1983), the questionnaire was both forward translated into Igbo and backward translated into English by two qualified persons whose knowledge of written 
and spoken Igbo and English was of adequate fluency level. All participants attended a 2-day youth empowerment seminar, organised by Foundation for the Training of Rural Youths (FOTRY) at the secretariat of the Local Government Development Centre, Nkwuesha, Nenwe, Enugu state. On the second day of the youth empowerment programme, the first author requested interested adolescents and young adults who indicated their willingness participate in the study to complete the questionnaire. Average time for the completion of the questionnaire was $7 \mathrm{~min}$. The research participants were informed that (a) responses would not be seen by their parents/guardians or significant others (b) responses should be private and they should not attempt to see others' answers or discuss responses while the survey was being completed (c) effort should be made to answer the question honestly. Completed questionnaires were returned to the researchers but $94 \%$ were properly completed and used for data analysis by the researchers.

\subsection{Design/Statistical Analysis}

This is a cross-sectional research. Data was analysed using Analysis Of Variance (ANOVA) and F-statistics was used to test for differences in resilience on account of age, gender and level of education.

\section{RESULTS}

In Table 1, adolescents had lower resilience scores $(54.29, \mathrm{SD}=11.27)$ than young adults $(72.26, \mathrm{SD}=13.69)$.
Males also had higher resilience scores than (74.84, SD = 15.37) than females $(58.06, \mathrm{SD}=12.24)$. Those with basic education had lower mean resilience $(56.58, \mathrm{SD}=12.00)$ than those with higher education $(76.13, \mathrm{SD}=12.85)$.

Table 2 indicates the test of the hypotheses by Fstatistics of ANOVA results. There was a significant difference in resilience of the participants on account of age. Young adults had significantly higher resilience scores than adolescents, $F(1,328)=12.11, \mathrm{p}<0.0$. The effect size showed that age accounted for $4 \%$ of the variance in resilience. There was no significant difference in resilience of males and females, $F(1,328)$ $=2.98$, although gender explained $1 \%$ of the variance in resilience. There was a significant difference in resilience between those who have lower educational attainment and those who have higher educational attainment. Participants with higher education had significantly higher resilience scores than those with lower education, $\mathrm{F}(1,328)=6.91, \mathrm{p}<0.01$. Education accounted for $2 \%$ of the variance in resilience. The interaction effect of age $*$ gender, age $*$ education and gender * education were not significant. Age, gender and education had a significant interaction effect on resilience, $\mathrm{F}(1,328)=1.81, \mathrm{p}<0.05$. Based on the interaction, for example, adolescent males with lower educational status had higher resilience scores than adolescent females with lower education. The variance explained by the significant interaction effect of the three variables was $2 \%$.

Table 1. Mean and standard deviation of resilience scores by age, gender and educational attainment.

\begin{tabular}{lllll}
\hline Variable & Group & $\mathrm{N}$ & Mean & SD \\
\hline Age & Adolescents & 162 & 54.29 & 11.27 \\
& Young adults & 167 & 72.26 & 13.69 \\
Gender & Male & 159 & 74.87 & 15.37 \\
& Female & 170 & 58.06 & 12.24 \\
Education & Basic & 214 & 56.58 & 12.00 \\
& Higher & 115 & 76.13 & 12.85 \\
\hline
\end{tabular}

Table 2. Tests of between subject effects of age, gender and educational attainment on resilience

\begin{tabular}{lcrrrc}
\hline Source & Type III SS & DF & Mean S & F & Effect size \\
\hline Age & 1431.67 & 1 & 1431.67 & $12.11^{* *}$ & 0.04 \\
Gender & 3151.92 & 1 & 3151.92 & 2.98 & 0.01 \\
Education & 817.33 & 1 & 817.33 & $6.91^{* *}$ & 0.02 \\
Age $*$ Gender & 444.32 & 1 & 444.32 & 5.76 & 0.01 \\
Age $*$ Education & 2.02 & 1 & 2.02 & 0.02 & 0.00 \\
Gender $*$ Education & 106.44 & 1 & 106.44 & 0.90 & 0.00 \\
Age $*$ Gender $*$ Education & 213.80 & 1 & 213.80 & $1.81^{*}$ & 0.02 \\
Error & 37944.62 & 321 & 118.21 & & \\
Total & 14010.97 & 329 & & & \\
Corrected total & 78103.78 & 328 & & &
\end{tabular}

p $<0.05 ;{ }^{* * *} \mathrm{p}<0.01$ 


\section{DISCUSSION}

In the present study, we examined the resilience of adolescents and young adults in an Igbo rural community, specifically testing for significant differences in resilience scores on account of age, gender and educational attainment. As far as age is concerned, we hypothesised that young adults will report higher resilience than adolescents. This hypothesis was supported by our finding, which replicates previous findings in other samples (Sun and Stewart, 2007; Gooding et al., 2011; Wagnild, 2011). It contradicts the findings of researchers (Condly, 2006; Schoon, 2006; Riches et al., 2009). Since adolescence is usually understood to be a period of storm and stress, the adolescent may not have acquired the cumulative capacity for thriving that may characterise young adulthood. For young adults, the enormous experience of adolescent transition may become useful in equipping the young person for the expectations and roles of the adult stage. The ability to thrive in adverse circumstances in a better way may have been learnt in the developmental process.

With regard to gender, we anticipated that Igbo adolescents and young adults who are males will have higher resilience scores than the females, which aligns with historically gendered views on individuals' capabilities, vulnerabilities and roles in traditional African societies. However, there was no significant difference in resilience of males and females in the total sample. Previous studies (Aronen and Kurkela, 1998; Campbell-Sills et al., 2006) have reported the lack of a significant difference in resilience of males and females, while others (Boardman et al., 2008; Stratta et al., 2013; Scoloveno, 2013; Ying et al., 2014) had reported that males were found to report more resilience than females. A number of explanations can be offered with regard to the finding in the current study. Most of the previous studies that found gender differences in resilience had investigated resilience in the western culture. Gender differences had not also been investigated in a combined sample of adolescents and young adults.

One may not be surprised by the lack of significant gender differences in resilience because females in Igbo society today enjoy greater equity with the males than they had in the past. This development is not unconnected with the increasing access to empowerment programmes in the process of socialisation. In the course of social relations, girls are encouraged to equally explore mutually empathic connections with caring and supportive adults who can foster their development of resilience as much as the males. Males and females are also encouraged to compete on equal basis for community resources and given opportunity for participation and engagement in community development programmes. Females are not shielded from challenging tasks and situations that provide opportunities for life-skills training and development. For example, contemporary Igbo society has appropriate social expectations of the capacity and behaviour of the young person whether male or female. Generally, the challenges and opportunities of growing up in a rural community.

For the influence of educational attainment on resilience, we expected that those who have higher educational attainment will report significantly higher resilience than those with lower educational attainment. This hypothesis was supported which is consistent with previous findings (Ma et al., 2013; Krasny et al., 2010). Apart from the primary gains of education in the acquisition of knowledge, there are tremendous benefits of higher levels of education in fostering of personality development through better access to social resources for the improvement of livelihood and quality of life. People with higher education may have greater resilience than those with lower education because the educated persons are more likely to have greater access to socio-economic facilitators of resilience and greater livelihood options. Those who pursue higher education are offered superb opportunities of interacting with positive adult models and supportive peers. The wider range of extra-curricular activities in the school and community for the better educated persons enable them to maintain meaningful relationships, aspire to achieve set goals and regulate their lives appropriately. The benefits of education as a resilience factor aligns with approaches to resilience as a social process that converts social goods into positive life outcomes for the individual and community.

There was no significant difference for the interaction effect of age $*$ gender, age $*$ education as well as gender * education. Age $*$ gender $*$ education had a significant interaction effect on resilience. This combined significance of the three variables are consistent with experiences with intervention programmes for enhancing resilience (Waaktaar et al., 2004), involving a mixture of risk, asset and process focused targets located in the child, family and community. Thus, a multi-systemic approach to resilience is advocated. For example, it was observed 
by the researchers that there were rural adolescent females who could not go further in their educational pursuits beyond the primary or basic education because of lack of financial support. In discussion with the authors, these individuals expressed their displeasure with the lack of a sustainable scholarship scheme in the community. It was learnt by the researchers that a foundation was set up to provide grants/scholarship for indigent students in the community between 2006 and 2010, but the scheme could not be sustained because it was substantially being funded by an individual. The local government authority and community development associations can rise up to the challenges of offering scholarships to those who demonstrate outstanding academic potentials and interest in higher education.

\section{LIMITATIONS OF THE STUDY}

The findings of this study should not be considered in isolation from its limitations. First, the study was cross-sectional in nature. Tremendous benefits in the study of resilience among young persons in rural communities can be gleaned from longitudinal research. Second, although there are promising research indicating that resilience could be made specific to certain functional outcomes such as school success (LaFromboise et al., 2006; Whitesell et al., 2009; Stumblingbear-Riddle and Romans, 2012), we did not particularise resilience to such functional areas because of the diverse demographic characteristics of the participants (e.g., primary and secondary school leavers, graduates, etc.). If future research is carried out using a homogenous sample, it may be useful to particularise resilience and adopt a measure that is designed as such. It is our hope that the present study inspires research interest on resilience in remote rural communities and similar populations. Such ventures will not only expand the frontiers of knowledge on resilience but also facilitate the development of comprehensive programmes for resilience promotion in rural communities.

\section{CONCLUSION}

This study is the first of its kind to have examined the resilience of Igbo rural adolescents and young adults. Findings of the study indicates that age and educational attainment significantly accounted for differences in resilience. Gender was not found to significantly explain differences in resilience. Age, gender and educational attainment significantly interacted to account for significant differences in resilience. Because of the social ecological nature of resilience, collaboration among families, schools, communities and government agencies to promote the resilience of young person's is advocated.

\section{ACKNOWLEDGEMENT}

We acknowledge the support of Foundation for the Training of Rural Youths in the course of the study.

\section{REFERENCES}

Abukari, Z. and J.A. Laser, 2013. Gender differences in academic outcomes among Ghanaian youth: The role of protective and risk factors. J. Community Psychol., 41: 117-138. DOI: 10.1002/jcop. 21518

Achebe, C., 1994. Things Fall Apart. 1st Edn., Knopf, New York, ISBN-10: 0385474547, pp: 209.

Ajaero, C.K. and I.A. Madu, 2013. Analysis of impacts of rural-urban migration on socioeconomic development of rural communities of south-eastern Nigeria. Int. J. Res. Arts Soc. Sci., 6: 433-449.

Anene, J.C., 1979. West Africa in the Nineteenth Century. In: Africa in the 19th and 20th centuries, Anene, J.C. and G. Brown (Eds.)., Nelson Publishers, London.

Arokiaraj, A.S., R. Nasir and W.S. Wan, 2011. Gender effects on self-esteem, family functioning and resilience among juvenile delinquents in Malaysia. Pertanika J. Soc. Sci. Humanit., 19: 1-8.

Aronen, E.T. and S.A. Kurkela, 1998. The predictors of competence in an adolescent sample: A 15year follow-up study. Nordic J. Psychiatry, 52: 203-212. DOI: 10.1080/08039489850139120

Abiola, T. and O. Udofia, 2011. Psychometric assessment of the Wagnild and Young's resilience scale in Kano, Nigeria. BMC Res., 4: 500-509. DOI: 10.1186/1756-0500-4-509

Ahmed, A.S., 2007. Post-traumatic stress disorder, resilience and vulnerability. Adv. Psychiatric Treatment, 13: 369-375. DOI: 10.1192/apt.bp.106.003

Boardman, J.D., C.L. Blalock and T.M.M. Button, 2008. Sex differences in the heritability of resilience. Twin Res. Human Genet., 11: 12-27. DOI: $10.1375 /$ twin.11.1.12 
Bolognini, M., B. Plancherel, W. Bettwshart and O. Halfon, 1996. Self-esteem and mental health in early adolescence: Development and gender difference. J. Adolescence, 19: 233-245. DOI: 10.1006/jado.1996.0022

Bronfenbrenner, U., 1979. The Ecology of Human Development: Experiments by Nature and Design. 1st Edn., Harvard University Press, Cambridge, MA., ISBN-10: 0674224574, pp: 368.

Campbell-Sills, L., S.L. Cohan and M.B. Stein, 2006. Relationship of resilience to personality, coping and psychiatric symptoms in young adults. Behav. Res. Therapy, 44: 585-599. DOI: 10.1016/j.brat.2005.05.001

Campbell-Sills, L., D.R. Forde and M.B. Stein, 2009. Demographic and childhood environmental predictors of resilience in a community sample. J. Psychiatry Res., 43: 1007-1012. DOI: 10.1016/j.jpsychires.2009.01.013

Condly, S.J., 2006. Resilience in children: A review of literature with implications for education. Urban Educ., 41: 211-36. DOI: 10.1177/0042085906287902

Chung, H. and M. Elias, 1996. Patterns of adolescent involvement in problem behaviors: Relationship to self-efficacy, social competence and life events. Am. J. Community Psychol., 24: 771-778. DOI: $10.1007 / \mathrm{BF} 02511034$

Davda, A., 2011. A pilot study into resilience. Ashridge Business School. Ashridge.

Douglas, S.P. and C.S. Craig, 1983. International Marketing Research. 1st Edn., Prentice Hall, Englewood Cliffs, N.J.

Epps, S. and B.J. Jackson, 2000. Empowered Families, Successful Children: Early Intervention Programs that Work. 1st Edn., American Psychological Association, Washington, DC., ISBN-10: 1557986592, pp: 287.

Frankenberg, E., B. Sikoki, C. Sumantri, W. Suriastini and D. Thomas, 2013. Education, vulnerability and resilience after a natural disaster. Ecol. Society, 18: 16-16. DOI: 10.5751/ES-05377180216

Frost, J. and S. McKelvie, 2004. Self-esteem and body satisfaction in male and female elementary school, high school and university students. Sex Roles, 51: 45-54. DOI: 10.1023/B:SERS.0000032308.90104.c6
Gamble, T.J. and E. Zigler, 1986. Effects of infant day care: Another look at the evidence. Am. J. Orthopsychiatry, 56: 26-42. DOI: 10.1111/j.19390025.1986.tb01540.x

GSCP, 2013. Why building resilience needs to be gender sensitive. Gender Standby Capacity Project. www.docs.unocha.org/sites/dms/Documents/Gender Toolkit1_7_GenderandResilience.pdf

Gianesini. G., M. Cusinato and W. Colesso, 2010. Resilience as a relational competence construct. Poster presentation at Pathways to Resilience II: The Social Ecology of Resilience Dalhousie University, Halifax, Nova Scotia, Canada.

Gooding, P.A., A. Hurst, J. Johnson and N. Tarrier, 2011. Psychological resilience in young and older adults. Int. J. Geriatric Psychol., 27: 262-70. DOI: $10.1002 / g p s .2712$

Grotberg, E.H., 2005. Resilience for tomorrow. Georgetown University.

Hair, E.C., J. Jager and S. Garret, 2001. Background for community-level work on social competency in adolescence: Reviewing the literature on contributing factors. Child Trends, Washington, DC.

Hampel, P. and F. Petermann, 2005. Age and gender effects on coping in children and adolescents. J. Youth Adolescence, 34: 73-83. DOI: 10.1007/s10964-005-3207-9

Holmes, R. and N. Jones, 2009. Gender inequality, risk and vulnerability in the rural economy: Refocusing the public works agenda to take account of economic and social risks. Background Report for SOFA 2010.

Howard, S. and B. Johnson, 2000. Resilient and NonResilient Behaviour in Adolescents. 1st Edn., Australian Institute of Criminology, ISBN-10: 0642242011, pp: 6.

Ibeagha, P.N., S.K. Balogun and G.A. Adejuwon, 2004. Resilience of inner-city Yoruba university undergraduates in South Western Nigeria. KamalRaj Stud. Tribes Tribals, 2: 125-129.

Ifeagwazi, C.M., J.C. Chukwuorji and E.A. Zacchaeus, 2014. Alienation and psychological wellbeing: Moderation by resilience. Soc. Indicators Res. DOI: $10.1007 / \mathrm{s} 11205-014-0602-1$

Krasny, M.E., C. Lundholm and R. Plummer, 2010. Resilience in social-ecological systems: The roles of learning and education. Environ. Educ. Res., 16: 463-474. DOI: 10.1080/13504622.2010.505416 
L'Abate, L., 2010. Resilience: A construct in search of a theory. Rivista di Studi Familiari, 2: 1-20.

L'Abate, L., M. Cusinato, E. Maino, W. Colesso and C. Scilletta, 2010. Relational Competence Theory: Research and Mental Health Applications. 1st Edn., Springer Science and Business Media, ISBN-10: 1441956654, pp: 344.

LaFromboise, T.D., D.R. Hoyt, L. Oliver and L.B. Whitbeck, 2006. Family, community and school influences on resilience among American Indian adolescents in the upper Midwest. J. Community Psychol., 34: 193-209. DOI: 10.1002/jcop.20090

Liddle, H., 1994. Contextualizing Resiliency. In: Educational Resilience in Inner City America: Challenges and Prospects, Wang, M.C. and E. Gorton (Eds.), Lawrence Erlbaum, Hillsdale, NJ., pp: 167-77.

Luthar, S., D. Cicchetti and B. Becker, 2000. The construct of resilience: A critical evaluation and guidelines for future work. Child Dev., 71: 543-562. DOI: 10.1111/1467-8624.00164

Ma, L., H. Chang, Y. Liu, H. Hsieh and L. Lo et al., 2013. The relationship between health-promoting behaviors and resilience in patients with chronic kidney disease. Scientific World J., 2013: 124973124979. DOI: $10.1155 / 2013 / 124973$

Masten, A.S., 1989. Resilience in development: Implications of the Study of Successful Adaptation for Developmental Psychopathology. In: The Emergence of a Discipline: Rochester Symposium on Developmental Psychopathology, Cicchetti, D. (Ed.), Lawrence Erlbaum Associates, Hillsdale, NJ., pp: 261-294.

Masten, A.S., 1994. Resilience in individual development: Successful adaptation despite risk and adversity. In: Educational resilience in inner-city America: Challenges and prospects, Wang, M.C. and E.W. Gordon (Eds.), Erlbaum, Hillsdale, NJ., pp: 3-25.

Masten, A.S., 2006. Developmental psychopathology: Pathways to the future. Int. J. Behav. Dev., 31: 4653. DOI: $10.1177 / 0165025406059974$

Masten, A.S., 2014. Invited commentary: Resilience and positive youth development frameworks in developmental science. J. Youth Adolescence, 43: 1018-1024. DOI: 10.1007/s10964-014-0118-7

Masten, A.S., K.M. Best and N. Garmezy, 1990. Resilience and development: Contributions from the study of children who overcome adversity. Dev. Psychopathol., 2: 425-444. DOI: 10.1017/S0954579400005812
Masten, A.S. and J.D. Coatsworth, 1998. The development of competence in favorable and unfavorable environments: Lessons from research on successful children. Am. Psychol., 53: 205-220. PMID: 9491748

Miller, J.B., 1986. Toward a new Psychology of Women. 1st Edn., Beacon Press, Boston, ISBN-10: 0807029092, pp: 154.

Netuveli, G., R.D. Wiggins, S.M. Montgomery, Z. Hildon and D. Blane, 2008. Mental Health and Resilience at Older Ages: Bouncing Back After Adversity in the British Household Panel Survey. J. Epidemiol. Community Health, 62: 987-991. PMID: 18854503

Newman, T., 2004. What Works in Building Resilience? 1st Edn., Barnardo's, Ilford, ISBN-10: 1904659020, pp: 115.

Newman, T. and S. Blackburn, 2002. Transitions in the Lives of Children and Young People: Resilience Factors. 1st Edn., Scottish Executive, Edinburgh, pp: 24.

Njoku, J.E.E., 1990. The Igbos of Nigeria: Ancient Rites, Changes and Survival. 1st Edn., E. Mellen Press, Lewiston, New York, ISBN-10: 0889461759, pp: 269.

Ofomata, G.E.K., 2010. The Igbo (Ndigbo): Vision, Mission and the Hereafter of a Survey of the Igbo Nation Project. In: A survey of the Igbo Nation, Ofomata, G.E.K. and C. Uwazurike (Eds.), pp: 1-23.

Ogbaa, K., 1995. Igbo. 1st Edn., Heritage Library of African Peoples, Rosen Publishing Group, New York.

Rew, L., M. Taylor-Seehafer, N.Y. Thomas and R.D. Yockey, 2001. Correlates of resilience in homeless adolescents. J. Nurs. Scholarship, 33: 33-40. DOI: 10.1111/j.1547-5069.2001.00033.x

Richardson, G.E., 2002. The metatheory of resilience and resiliency. J. Clin. Psychol., 58: 307-21. DOI: $10.1002 /$ jclp. 10020

Richardson, G.E. and P.J. Waite, 2002. Mental health promotion through resilience and resiliency education. Int. J. Emergent Mental Health, 4: 65- 75. PMID: 12014295

Riches, K., M. Acton, G. Moon and H. Ginns, 2009. Measuring resilience in childhood using data from the Tellus surveys. Res. Policy Plann., 27: 187-198.

Rutter, M., 1989. Pathways from childhood to adult life. J. Child Psychol. Psychiatry, 30: 25-51. DOI: 10.1111/j.1469-7610.1989.tb00768.x

Ryff, C.D., G.D. Love, M.J. Essex and B. Singer, 1998. Resilience in Adulthood and Later Life. In: Handbook of Aging and Mental Health: An Integrative Approach, Lomaranz, J. (Ed.), Plenum Press, New York, ISBN-10: 0306457504, pp: 69-96. 
Salazar-Pousada, D., D. Arroyo, L. Hidalgo, F.R. PerezLopez and P. Chedraui, 2010. Depressive symptoms and resilience among pregnant adolescents: A casecontrol study. Obstetr. Gynaecol. Int., 2010: 952493-952499. DOI: 10.1155/2010/952493

Schoon, I., 2006. Risk and Resilience: Adaptations in Changing Times. 1st Edn., Cambridge University Press, Cambridge, ISBN-10: 0521541565, pp: 244.

Scoloveno, R., 2013. Gender and resilience: Implications for nursing. The State University of New Jersey.

Sexton, T.L., C.W. Hanes and C.J. Kinser, 2010. Translating Science into Clinical Practice. In: Handbook of Clinical Psychology Competencies, Thomas, J.C. and M. Hersen (Eds.), Springer, New York, ISBN-10: 0387097562, pp: 153-180.

Shanahan, M.J. and S.M. Hofer, 2005. Social context in gene-environment interactions: Retrospect and prospect. J. Gerontol., 60: 65-76. DOI: 10.1093/geronb/60.Special_Issue_1.65

St. Jean, T., L. Tidman and I. Jerabek, 2001. Resilience test. Queendom.com.

Storer, J.H., C.M. Cychosz and B.L. Licklider, 1995. Rural school personnel's perception and categorization of children at risk: a multi-methodological account. Equity Excellence Educ., 28: 36-45. DOI: 10.1080/1066568950280206

Stratta, P., C. Capanna, S. Patriarca, S. de Cataldo and R.L. Bonanni et al., 2013. Resilience in adolescence: Gender differences two years after the earthquake of L'Aquila. Personality Individual Differences, 54: 327-331. DOI: 10.1016/J.PAID.2012.09.016

Stumblingbear-Riddle, G. and J.S.C. Romans, 2012. Resilience among urban American Indian adolescents: Exploration into the role of culture, self-esteem, subjective well-being and social support. Am. Ind. Alaska Native Mental Health Res., 19: 1-19. PMID: 22875470

Sumner, J., 2005. Sustainability and the Civil Commons: Rural Communities in the Age of Globalization. 1st Edn., University of Toronto Press, Toronto, ISBN10: 0802095275, pp: 179.

Sun, J. and D. Stewart, 2007. Age and gender effects on resilience in children and adolescents. Int. J. Mental Health Promot., 9: 16-25. DOI: 10.1080/14623730.2007.9721845

ThiMyThi, T. and R. Sha, 2013. Building disaster resilience from school level: A case study in Thua Thien Hue Province, Central Vietnam. J. Disaster Res., 8: 205-206.
Torma, L.M., 2010. Fibromyalgia pain and physical function: The influence of resilience. Ph.D. Thesis, Oregon Health and Science University

UNDP (2008). Human development report, 2007/2008. Palgrave Macmillan, New York.

Ungar, M., 2008. Resilience across cultures. British J. Social Work, 38: 218-35. DOI: 10.1093/bjsw/bcl343

UNICEF, 2013. Actions for children and youth resilience. Guide for governments. Panama City.

von Soest, T., S. Mossige, K. Stefansen and O. Hjemdal, 2010. A validation study of the Resilience Scale for Adolescents (READ). J. Psychopathol. Behav. Assessment, 32: 215-225. DOI: $10.1007 / \mathrm{s} 10862-009-9149-\mathrm{x}$

Waaktaar, T. and S. Torgersen, 2012. Genetic and environmental causes of variation in trait resilience in young people. Behav. Genet., 42: 366-377. DOI: 10.1007/s10519-011-9519-5

Waaktaar, T., H.J. Christie, A.I.H. Borge and S. Torgersen, 2004. How can young people's resilience be enhanced? Experiences from a clinical intervention project. Clin. Child Psychol. Psychiatry, 9: 167-183. DOI: 10.1177/1359104504041917

Wagnild, G., 2011. The Resilience Scale user's Guide. 3rd Edn., Resilience Centre, Worden, Montana, ISBN-10: 0615485707, pp: 125.

Wagnild, G. and H. Young, 1990. Resilience among older women. J. Nurs. Scholarship, 22: 252-255. DOI: $10.1111 /$ j.1547-5069.1990.tb00224.x

Wagnild, G. and H. Young, 1993. Development and psychometric evaluation of the Resilience Scale. J. Nurs. Measurement, 1: 165-178. PMID: 7850498

Wanberg, C. and J. Banas, 2000. Predictors and outcomes of openness to changes in a reorganizing workplace. J. Applied Psychol., 85: 13-142. DOI: 10.1037/0021-9010.85.1.132

Warner, R.B., 2009. Seven principles of building resilience: practical ways of growing through adversity. People Dynamics.

Weisner, B., P. Blaikie, T. Cannon and I. Davis, 2004. At risk. 1st Edn., Routledge, London.

Werner, E.E., 1985. Stress and Proteelive Factors in Children's Lives. In: Longitudinal Studies in Child Psychology and Psychiatry, Nicol, A.R. (Ed.), John Wiley and Sons, New York, ISBN-10: 0471104418, pp: 335-355. 
Whitesell, N.R., C.M. Mitchell, P. Spicer and VITPT, 2009. A longitudinal study of self-esteem, cultural identity and academic success among American Indian adolescents. Cultural Diversity Ethnic Minority Psychol., 15: 38-50. DOI: 10.1037/a0013456

Wild, L.G., A.J. Flisher and B.A. Robertson, 2011. Risk and resilience in orphaned adolescents living in a community affected by AIDS. Youth Society, 45: 140-162. DOI: 10.1177/0044118X11409256.
Ying, L., X. Wu, C. Lin and L. Jiang, 2014. Traumatic severity and trait resilience as predictors of posttraumatic stress disorder and depressive symptoms among adolescent survivors of the Wenchuan Earthquake. PLoS One, 9: e89401e89401. DOI: 10.1371/journal.pone.0089401

Young, C.C., 2012. Rural adolescent stressors and depressive symptoms. J. Rural Community Psychol. 